\title{
A Importância da Educação Ambiental na Escola Moisés Bom de Oliveira, Distrito de Morais, Araripina - PE
}

\author{
Maria Cristina Delmondes Nascimento ${ }^{l}$
}

Resumo: O presente trabalho teve como objetivo refletir sobre, como é tratado os tema transversal meio ambiente numa escola em Araripina, Pernambuco. Tratou-se de uma pesquisa descritiva, quantitativa e qualitativa. Os dados foram obtidos através de questionários. Os resultados demonstraram uma maior necessidade do envolvimento da família e da comunidade, tanto em projetos, como em ações que promovam o desenvolvimento de atitudes mais direcionadas ao cuidado ambiental.

Palavras-Chave: Meio Ambiente, Educação Formal, Preservação, Cidadania.

\section{The Importance of Environmental Education in School Bom Moisés De Oliveira Morais district, Araripina - PE}

\begin{abstract}
This study aimed to reflect on, how it is treated the cross-environment theme in a school in Araripina, Pernambuco. This was a descriptive, quantitative and qualitative research. Data were collected through questionnaires. The results showed a greater need to involve the family and the community, both in projects and in actions to promote the development of more targeted to environmental care attitudes.
\end{abstract}

Keywords: Environment, formal education, preservation, Citizenship.

\section{Introdução}

No decorrer da história da humanidade, a educação escolar tem sido apenas uma educação reprodutora dos fatos sociais, mas a realidade contemporânea permite-nos perceber que a escola como a instituição educacional mais importante da atualidade deveria contribuir na formação humana, porque a educação faz parte da vida e tem um papel importante na construção da cidadania.

Nas últimas décadas tem ocorrido um processo acelerado de mudanças nas esferas socioeconômicas e ambientais, essas mudanças contribuíram para extinção de muitas espécies de seres vivos, o que resultou no desequilíbrio de diversos ecossistemas da Terra.

\footnotetext{
${ }^{1}$ Mestranda em Ciências da Educação pela Universidade Lusófona - PT. Especialização em Docência do Ensino Superior. E-mail: Cristina_delmondes@hotmail.com;
} 
O número de pessoas pobres no mundo aumentou consideravelmente, assim como a exclusão social. O mundo, hoje, vive uma crise ambiental, resultante do processo acelerado de desenvolvimento da sociedade contemporânea, centrada no acúmulo de dinheiro e no consumismo demasiado.

Partindo dessa realidade é que consideramos importante a associação entre Educação Ambiental e educação escolar desde os anos iniciais do Ensino Fundamental, para a melhoria da qualidade do ensino e, conseqüentemente, da qualidade de vida de todos aqueles que participam da escola, isso porque numa concepção de Educação Ambiental Transformadora, a educação escolar é tida como ambiente de mudança social, onde ocorre uma transformação associada aos valores, aos padrões cognitivos, à ação política democrática e às relações econômicas. Essas mudanças fortalecem a identidade das pessoas através do exercício da cidadania, da percepção da totalidade das relações sociais no mundo e da superação das formas de dominação (REIGOTA, 2007).

Diante desse pressuposto, acreditamos que a Educação Ambiental pode contribuir para a formação emancipatória de todos os cidadãos, principalmente os do campo que se encontram excluídos dos processos de transformação social, submetidos a aceitarem tudo o que é posto pelo sistema político-financeiro que rege nosso país. Entretanto, na escola, a Educação Ambiental só poderá contribuir para a formação emancipatória desses cidadãos, se for desenvolvida como uma prática diária e, por isso, precisa ser iniciada na sala de aula, por professores e estudantes, e aos poucos conquistar outros espaços da escola, pois desta maneira ajudará o educando a ampliar sua visão de mundo, permitindo-lhe fazer leitura crítica e reflexiva de seu ambiente natural e social.

A pesquisa emerge a partir de nossa experiência enquanto professores de escolas do distrito de Morais do município de Araripina - PE, onde observamos que a maioria dos estudantes não valorizava o ambiente circundante, visto que, embora na escola tivesse um lixeiro em todas as salas de aula e uma lixeira maior fora das salas, percebemos que os arredores da escola estavam repletos de folhas de papel e embalagens de salgadinhos e doces, mas não só o tratamento que davam ao lixo que produziam, mas também, a falta de zelo pela a escola, pois apesar de ser um bem comum a todos, suas paredes e suas mesas encontram-se riscadas. Essa falta de atitudes e procedimentos que pudessem manter o ambiente limpo e saudável, reflete também nas relações interpessoais.

Dessa forma, percebe-se que os estudantes devem ter acesso a uma educação voltada para o Meio, para que possam se sentir parte tanto do meio natural quanto do meio social, enxergando sua importância e sua dependência na relação natureza/sociedade. Perante a essas observações foi que sentimos a necessidade de investigar se a Educação Ambiental desenvolvida pelos professores do terceiro e do quarto ano do Ensino Fundamental da escola pesquisada, tem contribuído para a formação de nossos alunos.

O objetivo primordial deste trabalho é abordar e considerar os aspectos físicos, culturais, tecnológicos e biológicos, e principalmente os modos de interação dos alunos com a natureza, por meio de suas relações sociais, do trabalho, da ciência e da tecnologia. Implantar um trabalho de 
Conscientização Ambiental que contemple as questões da vida cotidiana do aluno como cidadão e discuta algumas visões polemicas sobre essa temática. E averiguar, junto aos alunos os seus interesses pelo Meio Ambiente.

Para tanto, foi necessário identificar a concepção de meio ambiente e de Educação Ambiental dos professores, verificando como eles desenvolviam os temas relacionados ao meio ambiente, além disso, avaliamos ser importante, conhecer a concepção de meio ambiente dos estudantes.

A investigação teve uma abordagem qualitativa, por concordamos que em educação não devemos unicamente nos ater a dados quantitativos, pois " [...] parte-se do princípio de que no âmbito social existem diferentes problemáticas, questões e restrições que não podem ser explicadas nem compreendidas em toda a sua extensão a partir da abordagem quantitativa" (GONZAGA, 2005, p. 91). Visando identificar as concepções de meio ambiente e de Educação ambiental dos professores e verificar como são desenvolvidos os temas ambientais, utilizamos a entrevista estruturada, o questionário de perguntas abertas e a observação não-participante.

Temos certeza que essa pesquisa não solucionará os problemas educacionais nas escolas, mas, esperamos que as informações que constam nessa investigação possam abrir novos caminhos para reflexões sobre a importância da Educação Ambiental nessas escolas para a formação dos cidadãos conscientes da preservação do meio em razão de uma melhor qualidade de vida para todos.

\section{O que é Educação Ambiental}

A Educação Ambiental é definida como o processo que busca "desenvolver uma população que seja consciente e preocupada com o meio ambiente e com os problemas que lhe são associados, e que tenha conhecimentos, habilidades, atitudes, motivações e compromissos para trabalhar individual e coletivamente na busca de soluções para os problemas existentes e para a prevenção dos novos" (CAPITULO 36 da AGENDA 21, 1997).

Propõe-se que a Educação Ambiental seja um processo de formação dinâmico, permanente e participativo, onde as pessoas envolvidas passem a ser agentes transformadores, participando ativamente tanto do diagnóstico dos problemas quanto da busca de alternativas e da implementação de soluções.

Um dos eventos mundiais mais importantes para a Educação Ambiental foi a Conferência Intergovernamental de Educação Ambiental de Tbilisi, ocorrida em 1977, na ex-União Soviética. Apesar desta conferência ter acontecido a mais de vinte anos, suas diretrizes e propostas continuam sendo um dos marcos teóricos mundiais sobre Educação Ambiental. 
De acordo com a Conferência de Tbilise, as principais características da Educação Ambiental são (baseado no documento "Educação Ambiental" da Coordenação Ambiental do Ministério de Educação e Cultura, 2002):

1. Processo dinâmico interativo - é um processo permanente no qual os indivíduos e a comunidade tomam consciência do seu meio ambiente e adquirem o conhecimento, os valores, as habilidades, as experiências e a determinação que os torna aptos a agir, individual e coletivamente, e resolver problemas ambientais.

2.Transformadora - possibilita a aquisição de conhecimentos e habilidades capazes de induzir mudanças de atitudes. Objetiva a construção de uma nova visão das relações do ser humano com o seu meio e a adoção de novas posturas individuais e coletivas em relação ao ambiente. A consolidação de novos valores, conhecimentos, competências, habilidades e atitudes refletirá na implantação de uma nova ordem desenvolvimento sustentável.

3. Participativa - atua na sensibilização e na conscientização do cidadão, estimulando-o a participar dos processos coletivos.

4. Abrangente - extrapola as atividades internas da escola tradicional, deve ser oferecida continuamente em todas as fases do ensino formal, envolvendo a família e toda a coletividade. A eficácia virá na medida em que sua abrangência vai atingindo a totalidade dos grupos sociais.

5. Globalizadora - considera o ambiente em seus múltiplos aspectos : natural, tecnológico, social, econômico, político, histórico, cultural, técnico, moral, ético e estético. Deve atuar com visão ampla de alcance local, regional e global.

6. Permanente - tem um caráter permanente, pois a evolução do senso crítico e a compreensão da complexidade dos aspectos que envolvem as questões ambientais se dão de um modo crescente e contínuo, não se justificando sua interrupção. Despertada a consciência, ganha-se um aliado para a melhoria das condições de vida do planeta.

7. Contextualizadora - atua diretamente na realidade de cada comunidade, sem perder de vista a sua dimensão planetária ("Aja localmente, pense globalmente"). Além destas sete características definidas pela Conferência de Tbilise, existe uma oitava, mais recente, que envolve a necessidade de trabalhar a Educação Ambiental como um tema transversal dentro da escola. A questão da Educação Ambiental como tema transversal (incluída como um tema transversal nos Parâmetros Curriculares Nacionais) passou a ser elemento quase que obrigatório em todas as discussões, mesas redondas e análises recentes envolvendo Educação Ambiental no Brasil.

8. Transversal - propõe-se que as questões ambientais não sejam tratadas em uma disciplina específica mas sim que permeie os conteúdos, objetivos orientações didáticas em todas as disciplinas, no período de escolaridade obrigatória. 
Ainda de acordo com a Conferência de Tbilise, os princípios que devem nortear programas e projetos de trabalho em Educação Ambiental são (baseado no documento Educação Ambiental da Coordenação Ambiental do Ministério de Educação e Cultura, 2002):

- Considerar o ambiente em sua totalidade, ou seja, em seus aspectos naturais e artificiais, tecnológicos e sociais (econômico, político, técnico, histórico-cultural e estético);

- Construir-se num processo contínuo e permanente, iniciando na escola infantil e continuando através de todas as fases do ensino formal e não formal;

- Empregar o enfoque interdisciplinar, aproveitando o conteúdo específico de cada disciplina, para que se adquira uma perspectiva global e equilibrada;

- Examinar as principais questões ambientais em escala pessoal, local, nacional, regional, internacional, de modo que os educandos tomem conhecimento das condições ambientais de outras regiões geográficas;

- Concentrar-se nas situações ambientais atuais e futuras, tendo em conta também a perspectiva histórica;

- Insistir no valor e na necessidade de cooperação local, nacional e internacional, para prevenir e resolver os problemas ambientais;

- Considerar, de maneira clara, os aspectos ambientais nos planos de desenvolvimento e crescimento;

- Fazer com que os alunos participem na organização de suas experiências de aprendizagem, proporcionando-lhes oportunidade de tomar decisões e de acatar suas conseqüências;

- Estabelecer uma relação para os alunos de todas as idades, entre a sensibilização pelo ambiente, a aquisição de conhecimentos, a capacidade de resolver problemas e o esclarecimento dos valores, insistindo especialmente em sensibilizar os mais jovens sobre os problemas ambientais existentes em sua própria comunidade;

- Contribuir para que os alunos descubram os efeitos e as causas reais dos problemas ambientais;

- Salientar a complexidade dos problemas ambientais e, consequentemente a necessidade de desenvolver o sentido crítico e as aptidões necessárias para resolvêlos;

- Utilizar diferentes ambientes educativos e uma ampla gama de métodos para comunicar e adquirir conhecimentos sobre o meio ambiente, privilegiando as atividades práticas e as experiências pessoais.

\section{Aspectos Legais da Educação Ambiental}

A Constituição Federal do Brasil (1988), no seu artigo 225:

Todos têm direito ao meio ambiente ecologicamente equilibrado, bem de uso comum do povo e essencial à sadia qualidade de vida, impondo-se ao Poder Público e à coletividade o dever de defendê-lo e preservá-lo para as presentes e futuras gerações; cabendo ao Poder Público promover a Educação Ambiental em todos os níveis de ensino e a conscientização pública para a preservação do meio ambiente.

A Lei de Diretrizes e Bases (Lei 9.394/96) reafirma os propósitos constitucionais: 
A Educação Ambiental será considerada na concepção dos conteúdos curriculares de todos os níveis de ensino, sem constituir disciplina específica, implicando desenvolvimento de hábitos e atitudes sadias de conservação ambiental e respeito à natureza, a partir do cotidiano da vida, da escola e da sociedade.

O Presidente da República sancionou, dia 27 de abril de 1999, a lei que estabelece os princípios de educação a serem seguidos no país: enfoque holístico, democrático; concepção do meio ambiente sob o enfoque da sustentabilidade; pluralismo de ideais e concepções pedagógicas; vinculação entre a ética, educação, trabalho e as práticas sociais, além do reconhecimento e respeito à pluralidade e à diversidade individual, dentre outros (CARVALHO, 2008).

Esta lei institui também a Política Nacional de Educação Ambiental, considerada na educação formal e não formal, que deverão incluir a capacitação de recursos humanos, o desenvolvimento de estudos e pesquisas e a produção e divulgação de material educativo.

Nas escolas a Educação Ambiental deverá estar presente em todos os níveis de ensino, como tema transversal, sem constituir disciplina específica, como uma prática educativa integrada, envolvendo todos os professores, que deverão ser treinados para incluir o tema nos diversos assuntos tratados em sala de aula.

A Lei 9795, que cria a Política Nacional de Educação Ambiental, foi sancionada em 27 de abril de 1999. Apesar dessa lei significar um certo avanço, teve vetado seu artigo 18, que tratava da destinação de recursos. Além disso, sua regulamentação, que deveria ocorrer em um prazo de noventa dias após sua publicação, ainda não ocorreu. Sem regulamentação a Lei não pode ser aplicada (CARVALHO, 2008).

É muito importante que a sociedade civil se envolva no processo de discussão de sua regulamentação. O Decreto que deve regulamentar a Lei está em processo de discussão. O Conselho Nacional do Meio Ambiente (CONAMA) elaborou uma proposta de regulamentação. A Sociedade Civil pode e deve participar através dos Fóruns Estaduais, promovidos pelo Ministério do Meio Ambiente.

\section{A Prática Educativa da Educação Ambiental}

Dias (2008) afirma que é importante ressaltar que a Educação Ambiental é a prática educacional que ocorre em sintonia com a vida em sociedade, que pode (e deveria) ser inserida sob diversos enfoques: social, econômico, político, cultural, artístico etc., não podendo ser considerada como uma prática estanque, uma vez que abrange diversas áreas.

Desta forma também pode ser considerada como uma arte, no sentido de trabalhar com a criatividade no que tange procurar alternativas para envolver os indivíduos num processo de reeducação de valores, percepções e sentidos em relação a forma de ver e viver o mundo. 
Segundo Lima (2004) a Educação Ambiental está diretamente ligada a nossa forma de vida como um todo: desde o que comemos, como moramos, o que vestimos até o que consumimos.

Nossa postura frente ao cotidiano, nossas maneiras e até mesmo o nosso trabalho estão diretamente ligadas à Educação Ambiental. Partindo desta afirmação podemos perceber que a Educação Ambiental é um processo que deveria estar presente em todos os momentos de nossa vida, e não somente em ambientes escolares.

Educação Ambiental trata-se de um processo transformador e conscientizador que vai interferir de forma direta com hábitos e atitudes dos cidadãos. Partindo do princípio que a Educação Ambiental abrange todas as áreas, a cidadania tem fator fundamental para uma conscientização deste contexto global de Educação Ambiental. Segundo Dias (2008) "não é por falta de conhecimento que o meio ambiente é destruído, mas devido ao atual estágio de desenvolvimento existente nas relações sociais de nossa espécie". O que podemos perceber é que a destruição da natureza não resulta da forma como nossa espécie se relaciona com ela, mas da maneira como se relaciona consigo mesma.

Ao desmatar, queimar, poluir, utilizar ou desperdiçar recursos naturais ou energéticos, cada ser humano está reproduzindo o que aprendeu ao longo da história e cultura de seu povo, portanto, este não é um ato isolado de um ou outro indivíduo, mas reflete as relações sociais e tecnológicas de sua sociedade. Portanto, é impossível pretender que seres humanos explorados, injustiçados e desprovidos de seus direitos de cidadãos consigam compreender que não devam explorar outros seres vivos, como animais e plantas, considerados inferiores pelos humanos.

Carvalho (2008) afirma que os seres humanos normalmente sofrem as consequiências de suas próprias investidasmal planejadas, portanto, mal aplicadas. Muitos vivem em condições difíceis ou mesmo miseráveis. O sofrimento maior encontra-se nas favelas cercadas de lixo, situadas em lugares perigosos (em morros ou às margens de rios e arroios poluídos...). Todo esse sofrimento advém da má gestão das cidades, de poluição, do descaso de gestões descompromissadas e, da população em geral, que interfere de forma direta, na qualidade de vida dos indivíduos. Um meio ambiente poluído e devastado, não é lugar seguro, nem pode proporcionar condições de vida favoráveis.

Quando a Educação Ambiental não é percebida em seu todo, muitas vezes é aplicada como uma matéria estanque. Tomei conhecimento de inúmeros projetos de Educação Ambiental em escolas, empresas (e isso é muito bom), porém, sua forma estanque desvincula-a do seu todo, ou seja, é trabalhada com um enfoque de uma determinada questão e é só.

Existe uma preocupação por parte dos educadores em desenvolver projetos pedagógicos (matérias que devem ser trabalhadas) durante o ano letivo e muitos deles não conseguem globalizar a Educação Ambiental aos conteúdos curriculares. Por incrível que pareça, dar maior ênfase à Educação Ambiental pode parecer "perda de tempo", e isto ocorre por que o conceito de Educação Ambiental não está bem definido, seja por parte dos educadores, orientadores e ou coordenadores. A Educação Ambiental deve ser trabalhada de forma interdisciplinar (LIMA, 2004). 
Se tudo continuar como está, o prognóstico para um futuro próximo é desolador. Para se ter uma idéia, segundo o Programa Ambiental da ONU cerca de 1,5 quilômetros de floresta tropical é destruída a cada 6 minutos. Uma área do tamanho da Áustria é desmatada a cada ano. Uma árvore é plantada para cada dez que são derrubadas. Neste ritmo, toda floresta tropical será destruída até o ano 2035. Outro dado alarmante é que atualmente existem cerca de 500 milhões de automóveis em todo o mundo. Cada um destes automóveis consome, em média, 8 litros de combustível por dia e estima-se que por volta do ano 2025 haverá quatro vezes mais automóveis do que hoje. Sem falar da questão dos produtos descartáveis e embalagens não recicláveis que vêm aumentando assustadoramente abarrotando aterros sanitários. Portanto, a Educação Ambiental não é somente uma questão educacional e sim questão de VIDA, para que a vida sobreviva (DIAS, 2008).

A Educação Ambiental nas empresas é importantíssima e vai depender muito dos próprios empresários e do tipo de produtos que suas indústrias oferecem. Seria importante fazer uma análise do impacto ambiental ocasionado pela empresa e o que ela deveria efetivamente fazer para sanar os danos ambientais por ela causados. Partindo desta análise seria fundamental a instalação de um programa de Educação Ambiental que estivesse diretamente relacionado ao produto (como forma de ação imediata para sanar o dano causado e evitar novos danos) e a partir daí desenvolver a Educação Ambiental em seu todo.

Segundo Sorrentino (2002), na década de 70, governos internacionais preocupados com a rápida destruição dos recursos naturais e a poluição do planeta, defenderam a tese do crescimento zero, ou seja, congelar os níveis de progresso à época. Ora, por diversas vezes durante nossa história econômica, o Brasil teve crescimento abaixo de zero, portanto negativo, e nem por isso viu diminuindo seus problemas ambientais, muito pelo contrário. Devido à crise econômica, as empresas investiram menos em controle de poluição. A questão tecnológica também tem sido apontada como uma das responsáveis pela destruição ambiental, uma vez que polui, degrada o meio ambiente e desperdiça recursos naturais.

Ora, a tecnologia e a ciência não são neutras. Elas podem estar submetidas aos interesses dos detentores do poder naquele momento. Por outro lado, a adoção de tecnologia mais brandas e menos poluentes não asseguram uma relação menos predatória nas relações humanas.

É no dia a dia que a prática da Educação Ambiental faz-se mais necessária. São pequenos atos que dão início a grandes transformações. Uma vez que o indivíduo percebe com clareza a importância de hábitos e atitudes saudáveis tanto para si quanto para o meio, vai ser um exemplo para que mais pessoas tornem-se ambientalistas, o que todos somos por natureza, pois somos parte dela, porém, devido a inúmeros fatores, esquecemos disto. Aí entra também a questão da espiritualidade. Desenvolvendo valores espirituais, de valorização à vida, espontaneamente voltaremos a nos integrar com a natureza e consequentemente procuraremos preservar o meio ambiente, pois teremos uma noção clara de que tudo é integrado, tudo é interligado. (BRENDARIO, 1998). 
De acordo com Jesus e Martins (2002), nors orientam que, falar em Educação Ambiental é discutir de hábitos e atitudes. Propor mudanças não é uma coisa fácil, uma vez que esta deve ser espontânea.

Sendo assim, Educação Ambiental é muito mais do que conscientizar sobre o lixo, reciclagem e datas comemorativas. Ela será o elo entre todas as disciplinas e preencherá uma lacuna na área da educação que é a valorização da vida e, portanto, do meio ambiente.

\title{
Por que se preocupar em Educar Ambientalmente?
}

Quando você pensa em meio ambiente, você está inserido nele, ou não?

Para a maioria de nós, esta é uma pergunta realmente difícil de responder. Nossa educação não nos colocou como parte integrante do meio ambiente. Em uma reportagem de André Trigueiro jornalista do "O Globo" do dia 23/10/2006, sobre uma pesquisa que vem sendo feita em todo o território brasileiro de 4 em 4 anos desde a Rio 92, a respeito de meio ambiente, ele diz que:

\begin{abstract}
A riqueza e a complexidade do material coletado ainda são objeto de estudos, mas alguns dados merecem atenção desde já. Tal como haviam indicado as consultas feitas em 1992 e em 1997, a pesquisa confirmou em 2001 que, para a maioria dos brasileiros, meio ambiente é uma questão que se resume à fauna e à flora. Ao escolher, numa lista com catorze elementos, quais aqueles que fazem parte do meio ambiente, a maioria dos entrevistados deixou de fora "seres humanos", "favelas" e "cidades" (SOUZA, 2000, p.22).
\end{abstract}

Ou seja, aos olhos do brasileiro, meio ambiente é algo em que simplesmente ele não está incluído, e todos os problemas que dizem respeito à qualidade de vida nas cidades - lixo, saneamento, especulação imobiliária etc. - não estão relacionados com o assunto da entrevista.

Os solos do planeta Terra, estão passando por muitas mudanças desde sua criação, mas o ser humano está interferindo na velocidade natural destas transformações que ocorrem em eras, séculos, agora estão acontecendo em décadas. O ser humano está interferindo no fator TEMPO. As consequiências destes atos estão começando a surgir. A comunidade está sendo obrigada a conviver com fatos que desconhecia e que a estão assustando, como as intempéries do tempo, grandes enchentes, altas temperaturas, erosões, assoreamentos (MAIMON, 2003)

A noção de que os recursos naturais são esgotáveis é recente, é "novidade". Somente através da educação que a compreensão e o entendimento deste fato será alcançado. "É melhor prevenir, do que remediar" este dito popular deve ser sempre usado por nós humanos, precisamos aprender a prevenir, e para isto, é necessário conhecer, saber, entender, estudar, e então, recuperar.

Ainda segundo Maimon (2003): 
Recuperar as áreas de floresta, reflorestar para que as matas ao evaporarem, baixem a temperatura, tragam chuvas mais amenas, "segurem" as águas para que não "lavem" os solos; recuperar cidadania, para que o meio antrópico corra menos riscos, que o ser humano se respeite mais, e também tenha amor, amor pelo meio em que vive, pelo seu amigo, por seus companheiros de trabalho, por sua família... Porque quando se envolve com a Educação Ambiental envolve-se com uma mistura de palavras como: respeito, ética, educação, cidadania, compreensão, carinho, envolvimento, que para esta autora todas juntas se resumem em uma só palavra que é AMAR, amar da forma mais prazerosa que se pode ter, aquele amor que você dará e em troca receberá um MUNDO MELHOR (p.43).

Conceitos precisam ser mudados, preconceitos ignorados, é necessário ação, que se "meta a mão na massa", o trabalho de todos os seres humanos se faz necessário. Mas para isto de fato acontecer , é preciso que hajam mudanças de comportamento.

É neste ponto crucial que entra a Educação Ambiental, para SORRENTINO (2002), o desafio para quem deseja realizar a educação ambiental é o da sensibilização/ mobilização do grupo para o enfrentamento/ solução de problemas, é a construção de situações/ jogos/ simulações que nos permitam exercitar nossa capacidade de trabalho interdisciplinar e intersaberes, construindo conhecimentos e procedimentos que nos preparem para a tomada de decisões sobre os grandes impasses com que nos deparamos enquanto espécie humana e enquanto indivíduos.

Para a consolidação de atitudes e ações positivas em relação ao ambiente é cada vez mais importante que se compreenda como, quando e porque o problema ambiental está acontecendo e qual é o nosso papel para revertermos este quadro.

De acordo com Maimom (1993), o direito de propriedade está vinculado ao direito de uso de um recurso, ou seja, de cultivar uma plantação, de usar o meio ambiente.

Já para Santos (2002), o progresso trouxe consigo uma crescente degradação do meio, decorrente de um modelo econômico que privilegia a exploração incessante das riquezas naturais em prol do acúmulo de capital financeiro.

Diante deste quadro para Jesus e Martins (2002), é fundamental repensar a relação homemnatureza, o que implica conhecimentos, consciência, valores e atitudes.

A visão empresarial de que o lucro está acima dos interesses da comunidade, acima dos interesses ambientais, sociais, educacionais, de cidadania, enfim, esta idéia de que o objetivo principal é o monetário, tem que ser revisto.

A crise ambiental em que nos encontramos, não pode se basear na dificuldade em encontrar um ponto em comum entre o desenvolvimento e o sustento. É necessário que se ache este ponto que se chama desenvolvimento sustentável. Aos educadores resta mostrar como fazer para que se chegue a este patamar. Segundo Layrargues (2002), novas perspectivas da educação ambiental, que diametralmente rompem com o modelo convencional, é a hipótese de que só será possível proteger a natureza se ao mesmo tempo se transformar a sociedade, pois apenas reformá-la não seria suficiente. 
De acordo com Sorrentino (2002), o compromisso de cada um dos bilhões de habitantes deste planeta é essencial e insubstituível para a implementação das mudanças radicais que o momento exige. Os excluídos acabam por cobrar a parte que lhes cabe nesse latifúndio e o manifestam de diferentes maneiras. No mínimo, não se identificam com as decisões da "chefia" e não se responsabilizam por elas. Inúmeros são os exemplos de fracasso de belas iniciativas que não contaram com o comprometimento de todos os supostamente interessados. É preciso começar, podemos e devemos começar por nós mesmos.

\section{A Alfabetização Ecológica}

Para entender o mundo em termos sistêmicos, uma das principais premissas da alfabetização ecológica, é preciso desviar o foco dos conteúdos para os padrões. "seja pela literatura ou poesia, pelas artes visuais, dramáticas ou musicais; dificilmente existe algo mais eficaz do que a arte para desenvolver e aperfeiçoar a capacidade natural da criança de reconhecer e expressar padrões. As crianças são especialistas em criar visões de lugares que elas viram apenas na imaginação -lugares que ganham realidade pelo ato da criação . o que acontece quando sugerismo que ela "imaginem" lugares que de fatos existem e que encontrem poesias na água, na terra e na pedra enfim, que não apenas explore a beleza do lugar, mas também sintam uma ligação com ele. Vemos crianças encontrando os seus lugares, no mundo natural, crianças que sabem que a água não vem simplesmente da torneira, que sabem os nomes das plantas e dos animais à sua volta, que entende os desafios da vida sustentável na terra e conseguem instrumentos e usam a imaginação para responder a estes desafios. E vemos crianças que sabem o seu endereço ecológico tão bem quanto o nome das ruas e cidade em que moram. E passamos a ter a esperança. (STONE e BARLOW, 2006)

Nos últimos anos, a educação ambiental tem enfocado a crise e os problemas ambientais, como a poluição e extinção das espécies. David argumenta que ressaltar os problemas ambientais para as crianças, especialmente as menores pode levá-las a um sentimento de impotência e desesperança com a situação mundial e a sua capacidade de mudá-la. Acredita-se que as crianças que ama o ambiente em que vive, quando crescem se tornam cidadãos engajados e comprometidos com a preservação deste lugar (FRITJOF, 2006).

A sustentabilidade da vida se faz formando e nutrindo comunidades. Traduzindo para esfera humana. Traduzido para a esfera humana. Isso quer dizer respeito pela integridade cultural e pelos direitos básicos das comunidades á autodeterminação, auto-organização e acesso ao espaço, aos recursos naturais, as fontes de energia e outras para a satisfação das necessidades básicas. Imediatamente, pode-se ver que tudo isso envolve justiça ambiental, porque é exatamente isso que hoje falta a tantas comunidades mundo afora. E assim sustentabilidade e justiça ambiental estão na 
realidade profundamente interligadas. Viver de modo sustentável significar reconhecer que somos partes inseparáveis da teia da vida, das comunidades humanas e não-humanas, e que aumentar a dignidade e a sustentabilidade de uma comunidade significativa fortalece todas as outras. (STONE e BARLOW, 2006)

Acredito que a Alfabetização Ecológica contribui para a conscientização ecológica da sociedade. Pode colaborar ainda na construção de uma sociedade ecologicamente viável e socialmente justa. Alcançar tal objetivo é um grande desafio da educação ambiental na medida em que as mudanças necessárias na sociedade são, em parte, reflexo das mudanças que ocorrem nos indivíduos, tornando-se mudanças que são ao mesmo tempo individuais e coletivas.

Segundo Freire (1981), a Alfabetização Ecológica é a compreensão dos princípios de organização que os ecossistemas desenvolveram para sustentar a vida. Ensinar os princípios básicos da ecologia para nos tornarmos "ecologicamente alfabetizados", conhecendo as diversas redes de interações que constituem a teia da vida, são objetivos da alfabetização ecológica.

Através dela é possível compreender as múltiplas relações que se estabelecem entre todos os seres vivos e o ambiente onde vivem, e que tais relações, constituem a teia que sustenta a vida no nosso planeta.

\section{Metodologia}

Trata-se de um estudo exploratório, quantitativo e qualitativo. Adicionalmente foram levantados estudos bibliográficos sobre o tema, publicados em artigos, livros e Internet; publicações periódicas, como: jornais revistas, etc. Onde através destes obtivemos um aprofundamento do estudo, possibilitando ajustes ou fixação dos objetivos, formulação de hipóteses e redirecionamento da pesquisa de acordo com a relevância do tema.

O Local de estudo foi a Escola Moises Bom de Oliveira, rede municipal de ensino, localizada no Distrito de Morais, município de Araripina/PE. O objetivo foi identificar como os educadores trabalham com o tema transversal Meio Ambiente, suas metodologias, materiais utilizados, projetos desenvolvidos e suas concepções a respeito da temática.

Para isso, foram aplicados questionários a 5 professores e 20 alunos da Escola Nova Geração, Araripina/PE. A pesquisa realizou-se no período diurno, no período vespertino.

\section{Resultados e Discussão}


Com o objetivo de identificar na Escola da rede municipal de ensino Moises Bom de Oliveira, fontes de trabalho com o tema transversal Meio Ambiente, metodologias, materiais utilizados, projetos desenvolvidos e concepções a respeito da temática, foram aplicados questionários a todos os professores da unidade escolar e a 20 alunos do $1^{\circ}$ ao $5^{\circ}$ ano do Ensino Fundamental.

\section{Análise das Concepções de Educação Ambiental e de meio ambiente dos professores}

Dentre os professores entrevistados, observou-se que trabalham na escola com tempo de serviço entre 05 a 20 anos, alguns são formados nas áreas das disciplinas em que lecionam, e poucos possuem curso de especialização.

Iniciou-se indagando aos professores suas concepções a respeito do meio ambiente e educação ambiental, na qual a maioria dos educadores informou que Meio Ambiente é a Interação entre os seres vivos e a natureza. Já Educação Ambiental é a educação baseada nos estudos dos recursos naturais e necessidades de preservação, visando com isso formar indivíduos capazes de respeitar o espaço em que vive.

Quanto à pergunta: "Você trabalha o tema transversal meio ambiente e suas disciplinas?", $100 \%$ dos entrevistados responderam que sim, pois trabalham através dos conteúdos programados para a disciplina, como geografia (através da ecologia) e também abordando questões ambientais recentes através da confecção de maquetes, pesquisas, participação em projetos, produção de texto através da leitura de paradidáticos, etc.

Em relação às principais dificuldades enfrentadas para desenvolvê-las, obteve-se o seguinte:
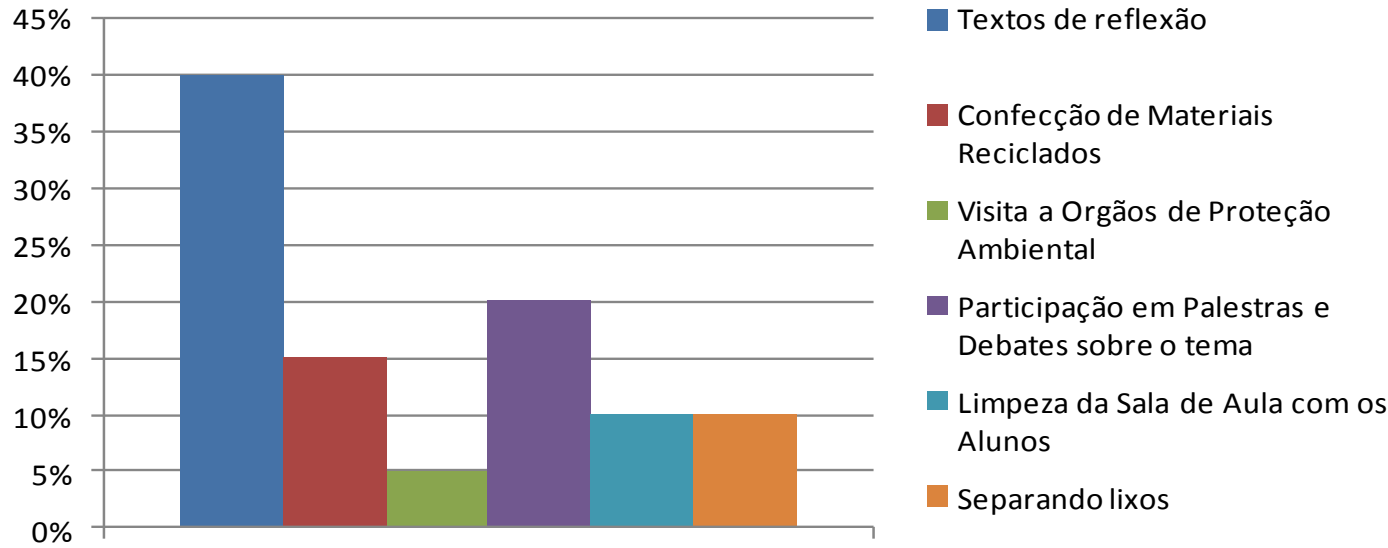

Separando lixos

Figura 01: Quais as principais dificuldades enfrentadas para desenvolvê-las? Fonte: Pesquisa Direta 
Percebe-se pela figura anterior que a maioria dos professores (40\%) trabalham o tema transversal meio ambiente através de textos de reflexão, seguido de participação e palestras e debates sobre o tema.

Questionando quanto à utilização dos PCN's de Meio Ambiente e Saúde em suas aulas, 100\% dos respondentes afirmaram que os utilizam.

Em relação à pergunta que trata sobre a importância dos temas ambientais na vida dos educandos, afirmar que estes temas visam sensibilizá-los que para ter-se uma vida saudável e feliz deve-se cuidar e preservar o meio ambiente.

Quanto às atitudes que podemos ter para colaborar na melhoria e conservação do meio ambiente, obteve-se o seguinte:

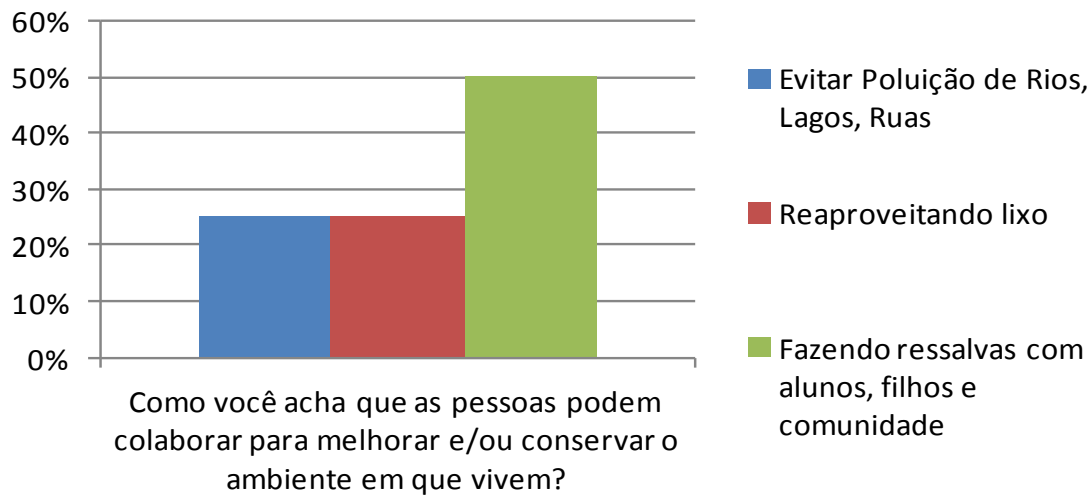

Figura 02: Como você acha que as pessoas podem colaborar para melhorar e/ou conservar o ambiente em que vivem?

Fonte: Pesquisa Direta

Compreende-se pela figura 02 acima que para melhorar e/ou conservar o ambiente em que vivemos, a escola deve manter uma parceria - escola, aluno, comunidade - isso seguido da ação individual de cada um em não poluir e preservar o meio ambiente

Indagando quanto ao que o professor tem feito para melhorar e/ou conservar o ambiente em que vive, afirmaram que: 


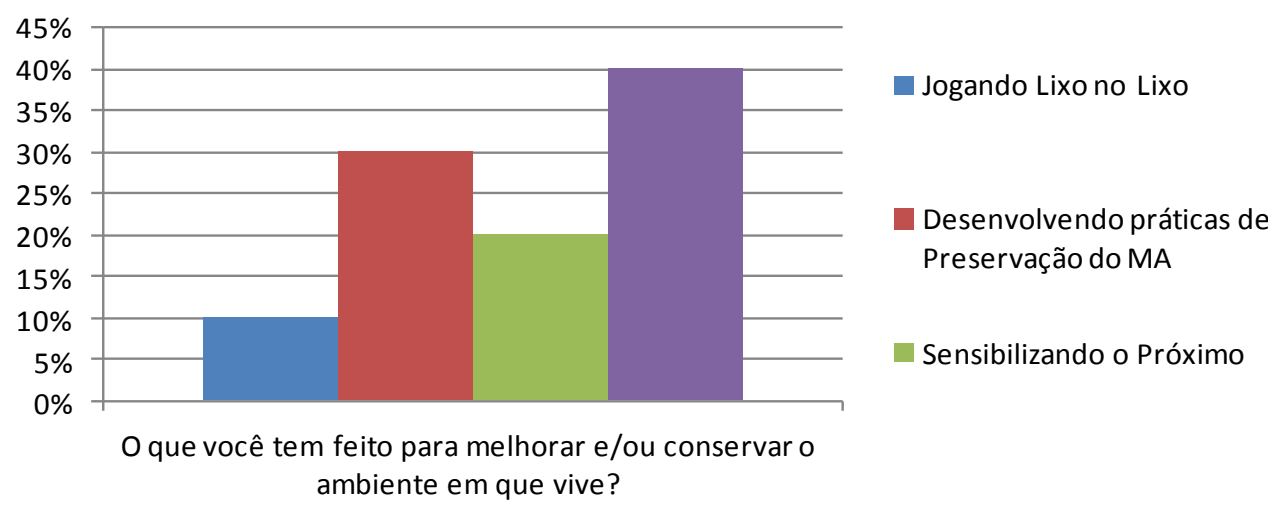

Figura 03: O que você tem feito para melhorar e/ou conservar o ambiente em que vive?

Fonte: Pesquisa Direta

Observa-se pelo questionamento acima que os professores fazem sua parte praticando os $5 \mathrm{Rs}$ além de sensibilizar os alunos a desenvolverem práticas de preservação.

\section{O meio ambiente na visão dos educandos}

O meio ambiente também é caracterizado por relações sociais e naturais. Essas relações interferem na vida dos educandos. Neste sentido, procuramos conhecer a concepção de meio ambiente dos estudantes da Escola Moises Bom de Oliveira.

Para os alunos do $1^{\circ}$ ano, foi solicitado que desenhassem o que entendiam por meio ambiente, onde foram selecionados os seguintes:

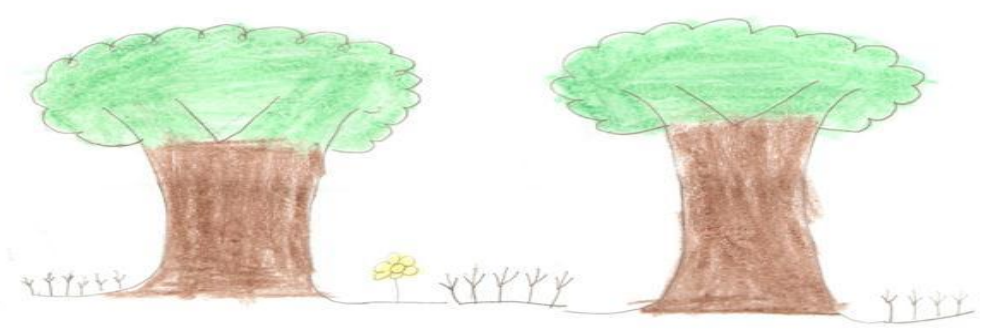

Figura 04: Desenho de uma criança do $1^{\circ}$ ano da Escola Moises Bom de Oliveira Fonte: Pesquisa Direta 


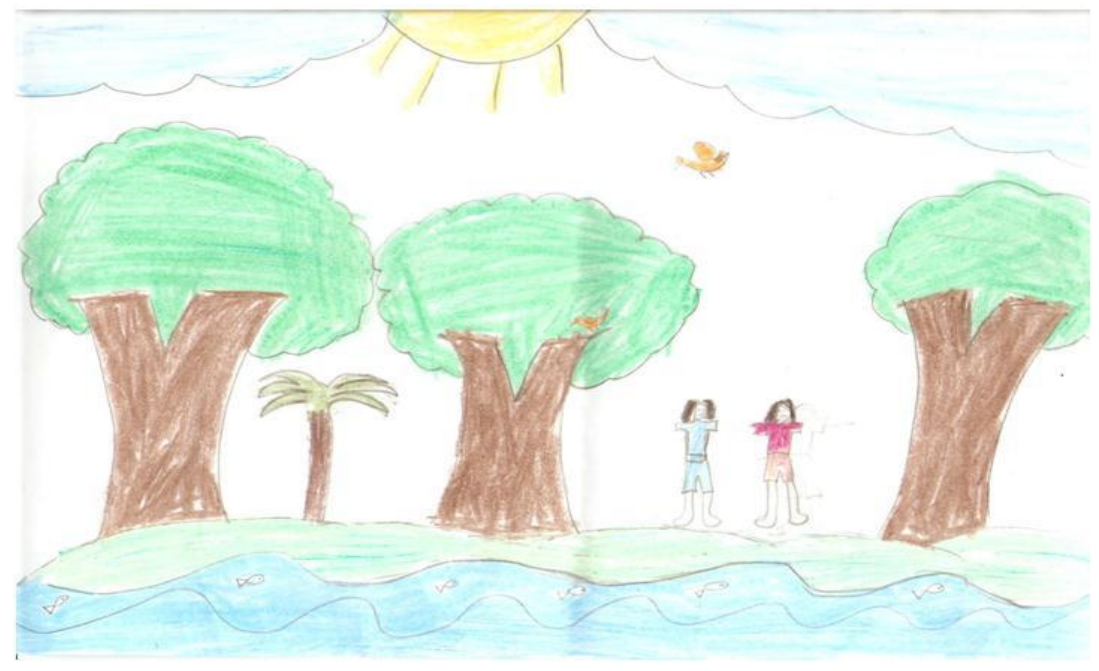

Figura 05: Desenho de uma criança do $1^{\circ}$ ano da Escola Moises Bom Fonte: Pesquisa Direta

Pelos desenhos pode-se observa-se que as crianças compreendem o que seja meio ambiente e o que faz parte dele, e desejam que estes seja sempre preservado.

Questionando aos das demais séries, sobre o que é meio ambiente, responderam que trata-se do meio em que vivemos e tudo aquilo vivo e não vivo que afeta o ser humano e a natureza: árvores, animais, ruas, rios, lagos, céu, vegetação, biodiversidade.

Em relação à pergunta: “O que faz parte do meio ambiente?”, obteve-se o seguinte:

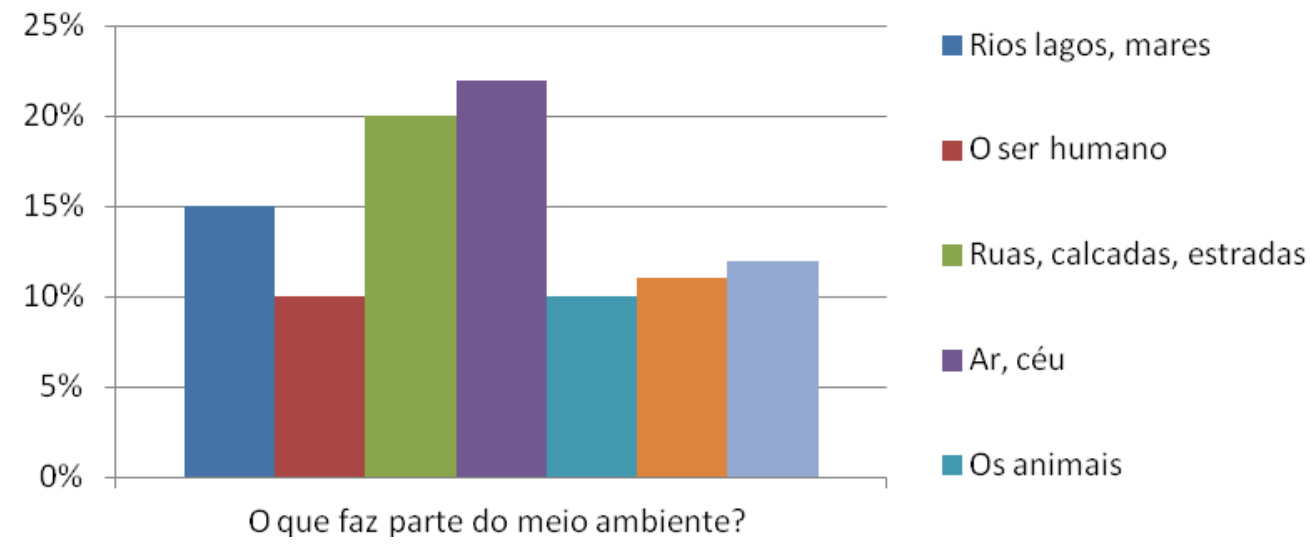

Figura 06: O que faz parte do meio ambiente? Fonte: Pesquisa Direta 
Segundo a figura acima, percebe-se que a maioria dos alunos possui uma concepção certa a respeito do que seja meio ambiente e o que faz parte dele.

$\mathrm{Na}$ qual costumam ter informações a respeito do meio ambiente, através de:

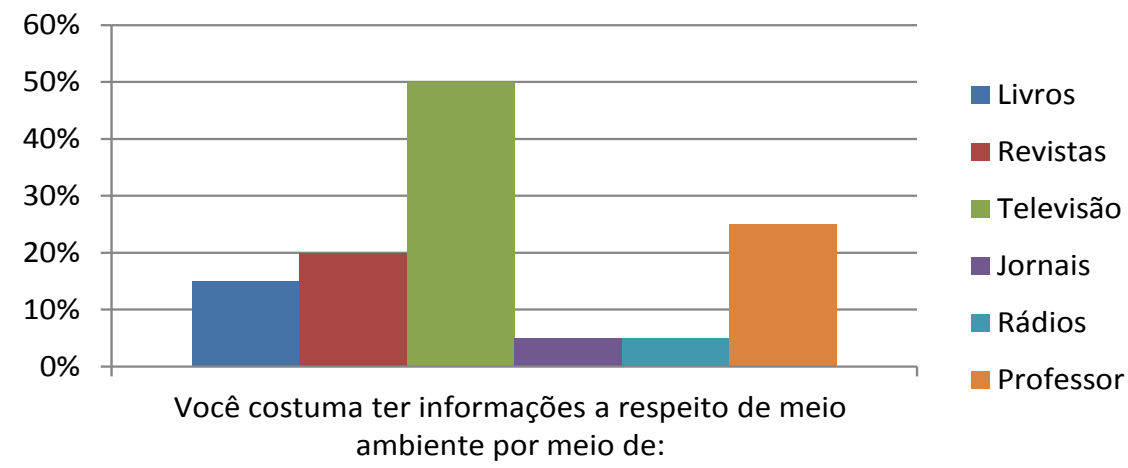

Figura 07: Você costuma ter informações a respeito de meio ambiente por meio de: Fonte: Pesquisa Direta

Observa-se pela figura acima que a maioria dos alunos afirmaram costumar receber informações sobre o meio ambiente através da televisão, ou seja, este recurso tecnológico influencia muito ainda no aprendizado e comportamento dos alunos.

Quanto ao que eles consideram como problemas ambientais afirmaram ser: a Poluição das águas, a falta de água, esgoto a céu aberto, fumaça de cigarros, enchentes e contaminação do solo. E para resolver estes problemas afirmaram que cientistas, políticos, comunidade e em especial ele próprio pode dar sua parcela de contribuição.

Foi indagado também se participam ou tem conhecimento do projeto reflorestamento, desenvolvido pela Escola, $80 \%$ dos alunos afirmaram que tem conhecimento e participam, através de aulas práticas plantando mudas e distribuindo-as na comunidade, além da realização de palestras, oficinas de reciclagem, desfile de roupas confeccionadas com material reciclado, etc.

Todos os alunos afirmaram que este projeto é de fundamental importância para a comunidade escolar, pois os incentivaram a preservar a escola, não acumular lixo, plantar mais e desmatar menos, preservando o bioma da caatinga.

Quanto ao que falta na escola para melhorar o projeto, afirmaram que mais incentivo financeiro, envolvimento da comunidade, mais assistência dos professores e a escola dispor de mais áreas verdes. 


\section{Conclusão}

Pela revisão de literatura abordada entendeu-se, que a Educação Ambiental define-se como toda a ação do homem, onde deve-se empreender ato de conscientização de seus semelhantes em favor da conservação, preservação da natureza.

Enquanto o homem não se conscientizar que ele é parte da natureza. Uma espécie da mesma, e não um ser fora dela, a natureza estará em perigo. Enquanto o homem não retirar a idéia de que a natureza está aqui para servi-lo, como quer nos fazer crer as religiões, a natureza estará em perigo.

De acordo com os resultados da pesquisa, percebeu-se que a educação também se preocupa com os problemas ambientais. Que estes vem se agravando cada vez mais com a ação do homem. E a escola tenta fazer sua parte, desenvolvendo projetos e aulas práticas. No entanto, para melhoria dessa prática, a escola necessita de incentivo financeiro, envolvimento da comunidade, assistência dos professores e maior participação dos alunos.

A educação ambiental é um instrumento político, que deve ser usado para que populações sejam esclarecidas sobre o modo de produção e reprodução do capitalismo. Não pode-se ter um futuro promissor, se continuarmos a nos mover dentro do sistema, como se não fosse da nossa conta a problemática do meio ambiente.

Deve-se com isso, escola, família e comunidade, tornarem-se mais conscientes e com uma percepção de que, se não desenvolvermos boas atitudes, não poderemos dar aos nossos descendentes uma vida de qualidade. Em virtude disso, espera-se que esta pesquisa impulsione mudanças educacionais nas escolas, que considerem a Educação Ambiental como um componente educacional indispensável, para o estudo e compreensão das relações presentes no meio ambiente.

\section{Referências}

AGENDA 21. Conferência das nações Unidas Sobre o Meio Ambiente e Desenvolvimento. 2 ed. Brasília. Senado Federal, 1997.

BRENDARIO, Celso. Cidadania e política Ambiental. Rio de Janeiro, 1998.

BRASIL. Constituição. Constituição da República Federativa do Brasil. Brasília, DF: Senado, 1988.

BRASIL. Lei no 9.394. Lei de Diretrizes e Bases da Educação Nacional. Brasília, DF: Congresso Nacional, 1996.

BRASIL. Política Nacional de Educação Ambiental. Lei no 9.795 de 27 de abril de 1999.

CARVALHO,Isabel Cristina de Moura. Educação Ambiental: a formação do sujeito ecológico. $4^{\mathrm{a}}$ Ed. São Paulo, 2008. 
DIAS, Genebaldo Freire. Educação Ambiental Princípios e Práticas. São Paulo: Editora Gaia, 2008.

EDUCAÇÃO AMBIENTAL: As grandes Orientações da Conferência de Tbilisi. Brasília. Instituto Brasileiro do Meio Ambiente e dos Recursos Naturais Renováveis, 2002.

FREIRE, Roberto. A Farsa Ecológica. Rio de Janeiro: Editora Guanabara Koogan S. A. 1981.

FRITJOF, Capra. Alfabetização Ecológica: A educação das crianças para um mundo sustentável. São Paulo, 2006.

GONZAGA, Amarildo Menezes. Contribuições para produções científicas. Manaus: BK, 2005.

LOUREIRO, Carlos Frederico Bernardo. Educação ambiental transformadora. In: LAYRARGUES, Philippe Pomier (coord.). Identidades da educação ambiental brasileira. Brasília: Ministério do Meio Ambiente, 2002.

JESUS, Cláudio Portilho de et al. Educação ambiental. Manaus: Universidade do Estado do Amazonas, 2002.

LIMA, Gustavo Ferreira da Costa. Educação, emancipação e sustentabilidade: em defesa de uma pedagogia libertadora para a educação ambiental. Brasília: Ministério do Meio Ambiente, 2004, p. $85-111$

MAIMOM, Edson Gomes. A prática da educação ambiental nas escolas. Porto Alegre: Mediação, 2003.

REIGOTA, Marcos. Meio Ambiente e Representação Social. $7^{a}$ Ed., São Paulo, 2007.

SORRENTINO, Rogério (org.). Legislação Brasileira do Meio Ambiente. Rio de Janeiro: DP\&A, 2002.

STONE, Alicia. BARLOW, J. Apresentação - cidadania ambiental. In: Ecopedagogia e cidadania planetária. 3. ed. São Paulo: Cortez: Instituto Paulo Freire, 2006.

SOUZA, N. M. Educação Ambiental: Dilemas da Prática Contemporânea. Rio de Janeiro: Thex Editora. Universidade Estácio de Sá, 2000.

Como citar este artigo (Formato ABNT):

NASCIMENTO, M.C.D. A importância da educação ambiental na escola Moisés Bom de Oliveira, Distrito de Morais, Araripina - PE. Id on Line Revista de Psicologia, Novembro de 2015, vol.9, n.28. p. 42- 60. ISSN 1981-1189.

Recebido: 12/09/2015

Aceito: 26/10/2015 